\title{
O performativo em Benveniste e Dufour
}

Resumo: A partir de um olhar sobre os efeitos da teoria da linguagem de Benveniste na composição da reflexão em um dos campos conexos, o da filosofia, este artigo visa compreender a singularidade da reflexão sobre o enunciado performativo no construto teórico de dois autores: Emile Benveniste e D-R, Dufour. Assim, a partir da (re)leitura de dois textos que tocam na distinção do par constativo-performativo, busca investigar que reflexões os unem ou distanciam. O estudo aponta para certo distanciamento da definição tradicional de performativo da escola de Oxford e para a convergência de ambos os autores para a definição de performativo como ato, acontecimento, único e irrepetível.

Palavras-chave: Enunciado; Performativo-constativo; Ato.

Title: The performative in Benveniste and Dufour

Abstract: From a perspective upon the effects of Benveniste's language theory in the structure of the reflection in one of the related fields - Philosophy -, this article aims to comprehend the singularity of the reflection upon the performative utterance in the work of two authors: Emile Benveniste and D-R, Dufour. Thus, from a (re)reading of two texts that revolve around the distinction of the pair constative-performative, it aims to investigate which reflections unite them or pull them apart. The article points out to a certain distance of the traditional definition of performative from Oxford School and to the convergence of both authors on the definition of performative as act, event, unique and unrepeatable.

Keywords: Utterance; Constative-Performative; Act.

\section{Primeiras palavras}

Este estudo tem origem no projeto de pesquisa Linguagem, tempo e sociedade, desenvolvido no âmbito do Programa de Pós-Graduação em Letras da Universidade de Passo Fundo, cujo interesse recai sobre questões que envolvem o homem, a linguagem, e a (inter)subjetividade.

Justificada a filiação, cabe informar o interesse deste texto, que se situa no segundo eixo proposto para este dossiê temático sobre as leituras de Emile Benveniste: o que pretende analisar os efeitos da teoria da linguagem de Benveniste na composição da reflexão de campos

\footnotetext{
1 Doutora em Linguística Aplicada (Unisinos). Professora do Programa de Pós-Graduação em Letras da Universidade de Passo Fundo. Orcid: http://orcid.org/0000-0003-4664-9625. E-mail: patriciav@upf.br.
} 
conexos, como o da filosofia.

Sabemos que Benveniste, embora tenha tido pouco reconhecimento entre os linguistas da sua época, conquistou importante espaço nas ciências humanas, uma vez que seus artigos são frequentes em publicações nas mais diversas áreas, como a psicologia, a antropologia, a psicanálise, a filosofia, entre outras, o que mostra que a natureza de seu pensamento sobre a linguagem ultrapassava os interesses da linguística (TEIXEIRA, 2012). Sua reflexão sobre a enunciação é inspiradora, porque, para além do diálogo com outras áreas, produz um retorno da linguística ao estudo da língua viva, do discurso, ou retorno à língua que serve para viver (TEIXEIRA; FLORES, 2011).

É por isso que entre os pesquisadores interessados no fenômeno da enunciação, Benveniste revela-se como linguista da maior amplitude, em razão, especialmente, do campo aberto pela admissão do falante na língua, o que remete à possibilidade de a linguística estar autorizada a construir conhecimento sobre o homem. (FLORES, 2019).

Reconhecida a potência do pensamento desse autor, cuja linguística se assenta em uma base antropológica, conforme esclarece Flores (2019), propomo-nos a revisitar um de seus textos controversos, A filosofia analítica e a linguagem, publicado em 1963, a fim de compreender a singularidade da reflexão do linguista sírio sobre o enunciado performativo ${ }^{2}$. Na sequência, (re)tomamos o primeiro capítulo, Eu-tu, da segunda parte da obra Os mistérios da trindade, de D-R. Dufour, intitulada $A$ trindade e a língua, com objetivo de investigar o que o filósofo diz sobre o enunciado performativo e em que medida sua compreensão desse tipo de enunciado se aproxima da definição de Benveniste ou da de Austin.

Com essa proposta, portanto, revisitamos esses dois textos que tocam na distinção do par constativo-performativo, a fim de investigar que reflexões acerca dos enunciados performativos aproximam-se ou se distanciam. É verdade que se trata de uma seleção parcial, um dado recorte dentro de um corpus teórico, o que nos leva a enfrentar as consequências de uma possível limitação da análise. Nesse sentido, assumimos o risco do empreendimento de uma redução de sentidos, como afirma Dufour (2000, p. 88), para quem "a ciência, qualquer que seja ela, é um empreendimento de redução".

Para dar conta do propósito deste estudo, organizamos a discussão em outras três seções, além dessa breve introdução: uma primeira, onde retomamos noções presentes no texto de Benveniste, trazendo à luz as reflexões que consideramos importantes, uma segunda, em que buscamos Dufour, com o mesmo propósito, e uma terceira em que apresentamos nossas considerações parciais com vistas a compreender aproximações e distanciamentos entre essa tríade de autores: Austin - Benveniste - Dufour.

Sem demora, apresentamos, na sequência, esse percurso.

\footnotetext{
${ }^{2}$ Ao longo do trabalho, por vezes fazemos referência ao par constativo-performativo. O enunciado constativo, entretanto, não será objeto de reflexão neste estudo. Se fazemos referência a este, é apenas no sentido de destacar aquele.
} 


\section{Emile Benveniste, um linguista preocupado com questões filosóficas}

Com a finalidade de compreender a singularidade da reflexão acerca do par constativoperformativo na construção teórica de Benveniste, chegamos ao texto $A$ filosofia analítica e a linguagem, publicado em 1963 em uma revista de estudos filosóficos (BENVENISTE, 1995). O artigo, que figura na quinta parte da obra Problemas de Linguística Geral ${ }^{3}$, intitulada $O$ homem na língua, inicia estabelecendo uma comparação entre o interesse comum do filósofo da linguagem e o do linguista para, na sequência, mostrar a especificidade do olhar do linguista.

Como encontramos, em outro texto de Benveniste (1995), publicado no mesmo ano, Vista d'olhos sobre o desenvolvimento da linguística, menção à especificidade da linguística em relação à filosofia, acreditamos ser possível inferir que o tema estivesse na esteira das preocupações do linguista à época. Em Vista d'olhos (1995), a menção a esta especificidade da linguística encontra-se em uma referência ao reconhecimento da filiação da linguística ocidental à filosofia grega, quando Benveniste explica que o interesse dos pensadores gregos pela língua se dava em torno de uma busca a respostas sobre a condição natural ou convencional da língua, um interesse, portanto, exclusivamente filosófico e não pelo funcionamento da língua.

Stumpf (2017), em estudo sobre o eufemismo e a enunciação ${ }^{4}$, defende que a performatividade é a característica que une o juramento e a blasfemia. Tal entendimento decorre da compreensão de que "algo se realiza por meio da enunciação". De acordo com a pesquisadora, o tema da performatividade, embora esteja presente de modo explícito no texto A filosofia analítica e a linguagem (1963), também é tematizado em textos anteriores, como em Da subjetividade na linguagem (1958) e Os verbos delocutivos (1958), além de ser um conceito importante no Vocabulário das Instituições Indo-europeias (STUMPF, 2017).

Em A filosofia analítica e a linguagem, texto cujo propósito é a reflexão sobre os performativos, o autor parece insistir em reafirmar a especificidade do olhar do linguista para as questões que envolvem a linguagem em uso. Os leitores de Benveniste sabem que esse texto foi (ainda é) objeto de duras críticas dentre os pesquisadores da grande área da linguística (OTTONI, 2002). Tais críticas acabam, por vezes, levando os leitores benvenistianos a evitarem esse texto, o que nos motivou a enfrentá-lo, em busca de respostas para a compreensão da instauração de tamanha crítica.

Importante observar que a publicação do texto de E. Benveniste ocorre cerca de apenas um ano depois da publicação da obra Quando dizer é fazer-palavras e ação e da obra Sentido e percepção, que reúne anotações de J. Austin e de participantes de palestras, seminários, cursos e conferências ministrados em Harvard e Oxford (OTTONI, 2002). Assim, perguntamo-nos: é possível que Benveniste não tenha compreendido profundamente as

\footnotetext{
${ }^{3}$ Doravante PLG I, quando se referir à obra publicada em 1966 e traduzida para o português brasileiro em 1995, ou PLG II, quando se referir à obra publicada em 1965, com tradução em 1989.

${ }^{4} \mathrm{Na}$ tese No limite do diálogo: eufemismo e enunciação em Émile Benveniste, Stumpf (2017) mostra que que a reflexão em torno do eufemismo em Benveniste está relacionada com a questão da blasfemia, do juramento e da performatividade.
} 
reflexões sobre o performativo produzidas pelos filósofos de Oxford? Ou será que Benveniste teria se interessado pelo funcionamento do performativo de modo diferente? É possível que, por vias diferentes, Austin e Benveniste estivessem preocupados com questões muito semelhantes? Tentaremos responder a estas questões neste artigo.

No texto A filosofia analítica e a linguagem, Benveniste (1995) introduz sua reflexão, fazendo referência aos filósofos da linguagem de Oxford, dentre os quais sabemos - e o autor confirma na sequência do texto - J. Austin é o principal representante. Tais filósofos, segundo Benveniste, dedicam-se à análise da linguagem comum, da linguagem em uso, em detrimento dos filósofos analíticos, que se preocupavam com a definição de modelos lógicos ou ideais que dessem conta de questões filosóficas ${ }^{5}$.

O linguista sírio reconhece o mérito dos estudos produzidos pelos representantes da escola de Oxford, em razão do que considera um ineditismo, desde os ensaios produzidos por Wittgenstein: "é a primeira vez que filósofos se entregam a uma pesquisa aprofundada sobre os recursos conceptuais de uma língua natural e trazem o espírito de objetividade, a curiosidade e a paciência necessárias" (BENVENISTE, 1995, p. 296). A partir daí, passa a explanar o estudo de Austin, que diferencia enunciados constativos de performativos. Através de exemplos e citações do filósofo britânico, Benveniste explicita a "fórmula" austiniana para identificar um enunciado performativo em condições "normais": a construção de enunciados que comportem um verbo na primeira pessoa do singular, no presente do indicativo, na voz ativa, como em "Batizo esse navio Liberdade. Desculpo-me. Dou-lhe as boas-vindas. Aconselho-o a fazê-lo" (BENVENISTE, 1995, p. 296); ou enunciados na voz passiva, e na segunda ou na terceira pessoa do presente do indicativo, como em "Pede-se aos passageiros que usem a passarela para atravessar as pistas" (BENVENISTE, 1995, p. 296).

Na sequência, continua a descrição da teoria de Austin, a qual prevê a possibilidade de ocorrência de outros enunciados, para além das formas que se aplicam à regra, como performativos, o que mostra certa flexibilidade entre o conceito de performativo e de constativo. É o caso, por exemplo, do imperativo "Feche a porta", que corresponderia à fórmula: "Ordeno-lhe que a feche", ou até mesmo à palavra "cão", que poderia agir como performativo ao significar "Aviso-os de que o cão vai atacá-los". A partir desses exemplos, segue uma citação direta que explica a possibilidade de ocorrem certos "azares do enunciado performativo", que poderiam anulá-lo, como é o caso de: 1) quem efetuar o enunciado não estar qualificado para tanto, 2) faltar-lhe autoridade ou 3) romper o compromisso estabelecido, o que revela possível dificuldade de manter a antítese constativo-performativo.

Feito esse breve resgate teórico, o linguista passa a tecer dura crítica à teoria dos filósofos de Oxford, exatamente neste ponto em que ocorrem os "azares" linguísticos que podem comprometer a distinção do par constativo-performativo:

Quer este (Austin) tenha ou não razão, depois de haver proposto uma distinção, e de se haver encarregado logo de diluí-la e enfraquecê-la a ponto de tornar-lhe

5 Ottoni (2002) mostra que a leitura de Benveniste tem seu mérito, entretanto Austin aborda a questão do sentido, do significado e da referência de maneira absolutamente original, o que produz verdadeiro impacto em questões da linguística descritiva e da filosofia tradicional da época. 
problemática a existência, ela continua a ser um fato de língua que serve de fundamento à análise no caso presente, e nós lhe atribuímos tanto maior interesse quanto (BENVENISTE, 1995, p. 298).

Se compreendemos bem, a crítica de Benveniste repousa tanto na suposta distinção de enunciados constativos e performativos, quanto na flexibilidade dessa definição. Para tecer sua argumentação, retoma exemplos de performativos como "Dou-lhe as boas vindas", "Desculpo-me", "Aconselho-o", levantando dúvidas sobre a performatividade desses enunciados que, segundo Benveniste (1995), banalizados na vida social, caíram ao nível de simples fórmulas e somente encontrariam sua função performativa se resgatado seu sentido primeiro. Desse modo, chega a rejeitar, ironicamente, exemplos de performativos em desuso: "antes de empreender essas exumações, estamos interessados em escolher performativos em pleno exercício que se prestam diretamente à análise" (BENVENISTE, 1995, 299-300).

A grande crítica de Benveniste se dá em torno de alguns aspectos da teoria, como é o caso, por exemplo, de fórmulas no imperativo que, para Austin, são classificados como performativos: "Dizer feche a porta é claramente tão performativo quanto dizer ordeno-lhe que a feche" (J.UMRSON apud BENVENISTE, 1995, p. 303). O linguista rejeita veementemente essa ocorrência como possibilidade de performativo: "Na realidade, é uma ilusão que corre o risco de criar o mais grave mal-entendido sobre a própria natureza do enunciado performativo" (BENVENISTE, 1995, p. 303).

Não pretendemos aqui justificar ou contrapor a argumentação de Benveniste acerca da definição de performativo da escola de Oxford. Nosso interesse se dá no principal argumento de Benveniste para a contestação da tese austiniana, que é a definição de enunciado como ato, este compreendido como acontecimento (não como ação).

É esse o tema/conceito (o de acontecimento, enunciado como ato) que parece interessar tanto a Dufour quanto a Benveniste, ao tratar do enunciado performativo, como pretendemos mostrar na sequência.

Para Benveniste, o enunciado performativo somente existe enquanto tal quando passa ser autentificado como ato:

Fora das circunstâncias que o tornam performativo, esse enunciado não é mais nada. Qualquer um pode gritar em praça pública: decreto a mobilização geral. Não podendo ser ato por falta da autoridade requerida, uma afirmação dessas não é mais que palavra; reduz-se a um clamor inane, criancice ou demência. Um enunciado performativo que não é ato não existe. (BENVENISTE, 1995, p. 301).

Desse modo, o atendimento ao critério de validade de um performativo enquanto tal, segundo Benveniste, estaria relacionado a dois aspectos, quais sejam: a pessoa que enuncia e a circunstância de enunciação. Isso supõe que os enunciados sejam proferidos por quem tem o direito de enunciá-los e que enuncia nas condições apropriadas. Dessa relação, decorre um outro aspecto que diz respeito à propriedade sui-referencial do ato performativo. Como ato, único, portanto, possui circunstâncias particulares: data e local definidos e a irrepetibilidade de ocorrência. "É acontecimento porque cria o acontecimento" (BENVENISTE, 1995, p. 302).

Benveniste dá sequência à sua argumentação, analisando enunciados performativos 
decorrentes do uso do verbo no imperativo, os quais visam agir sobre o ouvinte, intimandoIhe um comportamento. O emprego do verbo no imperativo não tem equivalência de enunciado performativo - explica - porque não é nem enunciado, uma vez que não serve para criar uma proposição com verbo pessoal, nem performativo, pois não denomina o ato que performa. Justifica sua argumentação, explicando que não é a produção de um comportamento do interlocutor (que obedece a uma ordem dada, por exemplo) que torna um enunciado performativo, senão a configuração de um ato. Essa explicação, que pode passar despercebida até mesmo pelo leitor mais atento, apresenta uma argumentação importante na medida em que se afasta radicalmente da definição austiniana de enunciado performativo. Se para os filósofos de Oxford, "Dizer feche a porta é claramente tão performativo quanto dizer ordeno-Ihe que a feche" (URMSON, 1962, apud BENVENISTE, 1995, p. 303), para Benveniste tal equivalência não passa de "uma ilusão que corre o risco de criar - mais grave mal-entendido sobre a própria natureza do enunciado performativo" (BENVENISTE, 1995, p. 303). O linguista alerta para a necessidade de se observar com mais atenção as modalidades de emprego linguístico que caracterizam o enunciado performativo. Tal como o compreende, o enunciado performativo é tão e somente performativo quando autentificado como ato, o que significa que deva cumprir certas exigências dentro das circunstâncias apropriadas que atendam a critérios de validade relativos à pessoa enunciadora e à circunstância de enunciação.

Na leitura que fazemos, pensamos que a recusa do linguista em aceitar a equivalência da forma do imperativo para a constituição do performativo (proposta austiniana) talvez possa justificar a polêmica em torno desse texto. Tentamos explicar melhor na sequência.

$O$ artigo de Benveniste contrapõe à visão da filosofia analítica uma perspectiva linguística. Benveniste propõe a manutenção da distinção do performativo-constativo em razão da existência de critérios formais, os quais justificam tal distinção. Na visão de Ottoni (2002), tal proposta produz um impasse insolúvel, pois ao mesmo tempo em que a discussão sobre a performatividade aproxima Benviste de Austin os distancia. Não queremos aprofundar os critérios que afetam a discordância dos autores acerca do performativo, tampouco o mérito dessa discussão. Interessa-nos, aqui, algo muito simples, que talvez passe até despercebido pelo leitor que chega desavisado ao texto de Benveniste, que é sua insistência na definição de performativo como ato/acontecimento. Salvo engano, parece-nos que Benveniste, ao apresentar sua própria definição para performativo, contrapondo-a, ainda que parcialmente, à definição de Austin, está delineando não o conceito de performativo, mas o conceito de enunciado e da própria enunciação, o que faz a partir da definição de performativo com ato, singularidade, acontecimento.

Quando justifica sua recusa à fórmula do imperativo, o linguista rechaça o efeito que pode ser produzido pelo uso da fórmula:

Não devemos enganar-nos pelo fato de que o imperativo produz um resultado, e de que Vem! Faz vir efetivamente aquele que se chama. O que conta não é esse resultado empírico. Um enunciado performativo não o é por poder modificar a situação de um indivíduo mas na medida em que é por si mesmo um ato. 0 enunciado é ato; aquele que o pronuncia cumpre o ato denominando-o. Nesse 
enunciado, a forma linguística é submetida a um modelo preciso, o do verbo no presente e na primeira pessoa. É totalmente diferente no imperativo. Estamos diante de uma modalidade específica do discurso; o imperativo não é denotativo e não visa a comunicar um conteúdo: caracteriza-se como pragmático e visa a agir sobre o ouvinte, a intimar-lhe um comportamento. O imperativo não é um tempo verbal; não comporta nem marca temporal nem referência pessoal. (BENVENISTE, 1995, p. 303, grifos do autor).

Nesse sentido, o que chama a atenção do leitor nessa recusa à fórmula do imperativo para caracterizar o performativo é a compreensão do linguista de enunciado (performativo, no caso) como ato único e singular. É interessante observar que, exatamente no mesmo ano em que publica esse texto, Benveniste parece bastante interessado na definição de enunciado (não na diferença entre constativo-performativo). É o que podemos inferir pela leitura de outro artigo, Vista d'olhos, especialmente na segunda parte. Quando Benveniste trata da especificidade da linguagem, encontramos a noção de ato de forma mais explícita, na afirmação de que a linguagem (re)produz a realidade. Sempre importante destacar esse prefixo (re) que não significa repetição, mas renovação. Nas palavras de Benveniste (1995, p. 26): "aquele que fala faz renascer pelo seu discurso o acontecimento e a sua experiência do acontecimento"

É verdade que Benveniste já havia formulado uma distinção entre ato e descrição do ato no texto Da subjetividade na linguagem, de 1958, o que nos leva a considerar que sua preocupação com o funcionamento do performativo não é inédita. É nesse texto que o linguista chama atenção para os "efeitos de sentido produzidos pela mudança das pessoas em certos verbos de palavras" (BENVENISTE, 1995, p. 292). Interessante que nesse texto parece haver bastante acordo com noções austinianas do performativo: "na enunciação je jure é o próprio ato que me compromete, não a descrição do ato que eu cumpro" (BENVENISTE, 1995, p. 292). Entretanto, já neste texto há uma definição de enunciação como ato, que talvez tenha nos passado despercebida em outras leituras: "A enunciação identifica-se com o próprio ato. Essa condição, porém, não se dá no sentido do verbo: é a 'subjetividade' do discurso que a torna possível" (BENVENISTE, 1995, p. 292).

Consideramos importante a observação de Ono (2007) acerca desta definição de enunciação que consta no texto Da subjetividade na linguagem:

Ora, je jure é uma forma de valor singular, por colocar sobre aquele que se enuncia eu a realidade de um juramento. Essa enunciação é um cumprimento: "jurar" consiste precisamente na enunciação eu juro, pela qual Ego está preso. A enunciação je jure é o próprio ato que me compromete, não a descrição do ato que eu cumpro. [...] A enunciação identifica-se com o próprio ato. (BENVENISTE, 1995, p. 292, grifos do autor).

Conforme a pesquisadora, esta é a primeira vez que a noção de enunciação é explicitamente vinculada à noção de ato. Entretanto, propõe um exame atento à tal noção, mostrando que, para Benveniste, a noção de enunciação nesse texto tem uma relação estreita com a relação com ego.

Desse modo, observando com atenção as ideias discutidas em torno de cinco anos 
antes da publicação do polêmico texto sobre os performativos, parece que Benveniste estaria muito mais interessado em definir um quadro que constitui a enunciação a partir da reflexão sobre a especificidade de sua constituição do que à distinção de performativo e constativo.

A formulação que o linguista dá à noção de enunciação no texto de 1970, texto onde condensa os mais de quarenta anos de reflexão linguística sobre a enunciação, conforme Flores (2013), parece bastante coerente com reflexões presentes nos textos de pouco mais de uma década que o antecede. Vejamos, a título de exemplo, pequenos recortes temporais que mostram a recorrência da preocupação com este tema.

Em Da subjetividade na linguagem (1958), vimos que "a enunciação identifica-se com o próprio ato" (BENVENISTE, 1995, p. 292).

Em A linguagem e a experiência humana (1965), "este ato de discurso que enuncia eu aparecerá, cada vez que ele é reproduzido, como o mesmo ato para aquele que o entende, mas apara aquele que o enuncia é cada vez um ato novo, ainda que repetido mil vezes" (BENVENISTE, 1989, p. 68).

Em A forma e o sentido na linguagem (1966), "a frase é cada vez um acontecimento diferente; ela não existe senão no instante em que é proferida e se apaga neste instante; é um acontecimento que desaparece" (BENVENISTE, 1989, p. 230).

Em Estruturalismo e linguística (1968), "Dizer bom dia todos os dias da vida a alguém é cada vez uma reinvenção" (BENVENISTE, 1989, p. 18).

Em Esta linguagem que faz história, "Falando nós nos referimos a situações que são sempre situações presentes ou situadas em função do presente, de modo que, quando evocamos o passado, é sempre no seio do presente" (BENVENISTE, 1989, p. 32).

Em O aparelho formal da enunciação (1970), "a enunciação é este colocar em funcionamento a língua por um ato individual de utilização. (...) É preciso ter cuidado com a condição específica da enunciação: é o ato mesmo de produzir um enunciado e não o texto do enunciado, que é nosso objeto." (BENVENISTE, 1989, p. 82).

Observamos que, em todos esses textos, há uma persistência na definição da enunciação como ato, acontecimento, único e individual está sempre presente, noção que não parece ser mero detalhe na reflexão do autor.

\section{A definição de performativo em Dufour filia-se a Austin ou a Benveniste?}

Chegamos à obra Os mistérios da trindade, de Dufour (2000), mais especificamente ao primeiro capítulo da segunda parte, intitulado $\mathrm{A}$ trindade e a língua, dedicado à díade $E$ u-tu, interessados na especificidade da reflexão do autor acerca do enunciado performativo.

A obra, publicada na França em 1990, resulta de uma pesquisa original que, conforme Mendonça (2013), mostra "a existência de uma forma trinitária imanente, inscrita em nossa condição de ser falante, configurando um pensamento trinitário que conheceu múltiplas atualizações ao longo da História do Pensamento" (s.p). De acordo com a psicanalista, a leitura da obra "sugere e incita uma leitura transversal, que permita a cada leitor avançar ou recua no texto, traçando seu caminho particular, de acordo com as questões que o concernem" 
(MENDONÇA, 2013, s.p).

Dufour (2000, p. 70) reconhece em Benveniste uma característica singular que o diferencia dos demais pensadores no que se refere ao tratamento das formas pronominais. A teorização do linguista "não cede às banalidades filosóficas, como também não se perde nas derivas linguísticas hipertecnicistas." São duas fórmulas que constituem o axioma da análise empreendida por Benveniste acerca de sua reflexão sobre a comunicação e a temporalidade: "é eu quem diz eu" e "'eu' não é nem 'tu' nem 'ele'”. É assim que Dufour compreende a organização da V Parte de PLG I.

O capítulo escolhido para a construção do caminho de leitura que traçamos é dedicado à díade eu-tu, que integra o que Dufour nomeia de dispositivo intralinguístico, criado por Benveniste para descrever a constituição do ato de fala:

Falar - para dizer o que se quer, qualquer coisa, ou questionar o uso da fala - é, assim, fundar ipso facto um direito: falar é usar "eu", e usar "eu" é reconhecer-se mutuamente o direito à fala, a propósito do qual, evidentemente, ninguém pede contas (DUFOUR, 2000, p. 77, grifos do autor).

É a possibilidade de fazer uso da fala que nos permite participar do grande jogo da interlocução, esse espaço-tempo que permite a troca de objetos entre dois protagonistas, já que falar consiste em trocar a capacidade de dizer 'eu'; como declara Dufour (2000), encontrar seu gozo próprio: "É este gozo, perdido desde que encontrado, que procuramos em cada uma das nossas alocuções, sob a troca obstinada e vã dos objetos, diversos, heteróclitos, que nosso discurso carreia" (DUFOUR, 2000, p. 80). Essa experiência do falar remete a uma condição exclusivamente humana e revela a presença da língua nele (FLORES, 2019).

Teixeira e Messa (2015) defendem, a partir de Flores (2013, p. 197), que os estudos de Benveniste acerca da enunciação se vinculam a uma "reflexão maior sobre a natureza da linguagem", o que revela a premissa de uma visão antropológica que pressupõe a interrelação entre linguagem, homem, cultura e sociedade. Nesse sentido, as autoras propõem-se a examinar a amplitude da noção de enunciação em Benveniste, uma vez que esta "é formulada sob uma perspectiva dialógica, que não desconsidera as relações entre linguagem, (inter)subjetividade, cultura e sociedade" (TEIXEIRA; MESSA, 2015, p. 9). Tal interpretação se dá a partir da leitura de Barthes, para quem Benveniste, longe de atribuir uma função utilitarista à língua, como simples instrumento de comunicação, compreende uma língua que está na natureza do homem, uma língua que serve para viver. A partir de recortes de diversos textos que se encontram nos PLG I e II, as autoras comprovam o diálogo como constitutivo da natureza humana da linguagem e argumentam que "a abertura à dimensão dialógica desfaz a antinomia entre o eu e o outro, o indivíduo e a sociedade". (TEIXEIRA; MESSA, 2015, p. 10). Essa é também a compreensão de Flores (2013) para quem a condição humana está vinculada à capacidade da linguagem e da intersubjetividade, o que revela a natureza antropológica da enunciação.

É essa visada antropológica da enunciação, via discussão acerca do performativo, que depreendemos da leitura de Dufour. Não encontramos, no texto do filósofo francês, referência explícita à distinção do par constativo-performativo tal como formulada por Austin, 
o que nos leva a inferir algumas possibilidades: a de este (Dufour) concordar, ainda que em parte, com Austin; a de não desejar aprofundar discussão nesse texto; ou de, simplesmente, não dar a esse tema destaque especial. Nesse sentido, o que encontramos nesse texto é uma crítica à atualização da definição de performativo de Pierre Bourdieu ${ }^{6}$, para quem os enunciados sui-referenciais estariam condicionados à validação no social, isto é, quando pronunciados por quem de direito, como convém, no caso um juiz pronunciando "eu o condeno". Tal enunciado seria legitimado socialmente, pois há instituições que garantem que a sentença seja executada. (DUFOUR, 2000).

Dufour discorda explicitamente desta definição, que, na sua leitura: "(a definição) esquece a evidência na qual nos produzimos como sujeito - de que qualquer um tem autoridade para executar um ato de fala" (DUFOUR, 2000, p. 81). Não precisamos de autorização para falar, declara Dufour, discordando de P. Bourdieu. E é a partir de E. Benveniste que Dufour (2000, p. 81 , grifos do autor) defende que qualquer pessoa tem autoridade para executar um ato de fala:

tal é o sentido da fórmula de Benveniste sobre os índices "eu" e "tu", que não têm que satisfazer a condição de verdade e que entram no mundo antes de todo controle. (...) O autor da fala jamais tem que fazer a demonstração da legitimidade de sua pretensão a falar.

Tal reflexão certamente está muito mais centrada na relação entre homem e linguagem presente no texto benvenistiano de 1958 (Da subjetividade na linguagem) do que na definição de enunciado constativo-performativo de Austin, ao menos do modo como a discussão se revela no texto em que Benveniste tece sua crítica à filosofia analítica em 1963.

\section{Palavras quase finais}

Assim, revisitando esses dois textos que tocam na distinção do par constativoperformativo, a fim de investigar que aspectos da reflexão os une ou distancia, arriscamo-nos a afirmar que Dufour e Benveniste, por vias diferentes, retomam aspectos relacionados à definição de performativo austiniana. Se Benveniste tece sua crítica de forma mais explícita, talvez a tenha construído justamente porque estivesse mais preocupado com a definição do conceito de enunciação, o qual começa a delinear nesse período e toma toda sua forma e importância no texto de 1970, quando afirma que as condições do empregos das formas não são iguais às condições de emprego da língua, que a enunciação é "ato individual de apropriação da língua que introduz aquele que fala em sua fala" (BENVENISTE, 1989, p. 84).

Em Dufour encontramos a metáfora de que a comunicação intersubjetiva possibilita o preenchimento dos signos eu-tu, conchas vazias que se tornam cheias quando alguém fala. Além disso, as condições de uso desses signos não parecem assumir importância, já que

\footnotetext{
${ }^{6}$ Dufour (2000) mostra a problemática da reflexão de Bourdieu acerca da noção de performativo. O sociólogo francês recupera a noção austiniana de performativo, apresentando uma nova definição de, não mais "dizer é fazer", mas "um dizer que substitui o fazer".
} 
"enquanto falante, qualquer um tem autoridade para executar um ato de fala e usar o índice 'eu'” (DUFOUR, 2000, p. 81, grifos do autor). A definição de Dufour parece esclarecer os pontos em aberto na teorização de E. Benveniste. Se Dufour tem razão em afirmar que qualquer um tem autoridade para usar executar um ato de fala e usar o índice eu, talvez seja porque a leitura que faz da teoria de Benveniste possua uma visada antropológica, que coloca o homem e a linguagem na centralidade da reflexão. A leitura que compreende o fundamento antropológico na constituição da reflexão benvenistiana é defendida por Flores (2019, p. 246) para quem as ideias de Benveniste constituem uma antropologia da enunciação, na medida em que tecem "um saber sobre o homem que advém de sua capacidade de enunciar" (FLORES, 2019, p. 246).

Para finalizar esta reflexão, pensamos que é possível encontrar, na relação que depreendemos da leitura desses dois textos: A filosofia analítica e a linguagem, de E. Benveniste, e Eu-tu, de D-R. Dufour, os quais foram produzidos em um intervalo de quase 40 anos, não uma simples rejeição à definição do par constativo-performativo da escola de Oxford, mas uma persistência da noção de enunciação como acontecimento, como ato, evento único. Acreditamos que a definição de Benveniste para performativo como ato encontra eco em Dufour, pois a enunciação se institui na relação intersubjetiva que se estabelece entre o par eu-tu, quando estes estabelecem uma troca, isto é, a inversão da qualidade específica do eu. Poder dizer eu é condição exclusivamente humana, ensina Benveniste. Sendo assim, acreditamos que a definição de performativo como ato, único portanto, em Benveniste e em Dufour, remete à dimensão antropológica do homem na língua, conforme Flores (2019, p. 259), a uma antropologia da enunciação, "do dizer do homem acerca da presença da língua nele".

\section{Referências}

BENVENISTE, É. Problemas de Linguística Geral I. Campinas, SP: Pontes Editores, 1995.

BENVENISTE, É. Problemas de Linguística geral II. Campinas, SP: Pontes Editores, 1989.

DUFOUR, D-R. Os mistérios da trindade. Rio de Janeiro: Companhia de Freud, 2000.

FLORES, V.N. Introdução à teoria enunciativa de Benveniste. São Paulo: Parábola, 2013.

FLORES, V. N. Problemas gerais de linguística. Petrópolis, Rio de Janeiro: Editora Vozes, 2019.

MENDONÇA, T. Os Mistérios da Trindade de Dany-Robert Dufour, Companhia de Freud. Jornal O Globo, Rio de Janeiro, s.p., 2013. Disponível em: http://www.iecomplex.com.br/uploads/resenha\%20Trindade.htm Acesso em: 08 set. 2019.

ONO, A. La notion d'énonciation chez Émile Benveniste. Limoges: Lambert-Lucas, 2007.

OTTONI, P. R. John Langshaw Austin e a Visão Perfomativa da Linguagem. DELTA. Documentação de Estudos em Lingüística Teórica e Aplicada, v. 18, n. 1, p. 117-143, 2002.

STUMPF, E. No limite do diálogo: eufemismo e enunciação em Émile Benveniste. 2017. 118 f. Tese (Doutorado em Estudos da Linguagem) - Programa de Pós-Graduação em Letras, 
Universidade Federal do Rio Grande do Sul, Porto Alegre, 2017.

TEIXEIRA, M. O estudo dos pronomes em Benveniste e o projeto de uma ciência geral do homem. Revista Desenredo, v. 8, n. 1, p. 71-83, 2012.

TEIXEIRA, M; FLORES, V. Linguística da Enunciação: uma entrevista com Marlene Teixeira e Valdir Flores. ReVEL, v. 9, n. 16, p. 406-425, 2011.

TEIXEIRA, M.; MESSA, R. M. Émile Benveniste: uma semântica do homem que fala. Estudos da Língua(gem), v. 13, n. 1, p. 97-116, 2015.

Recebido em: 14/11/2019. Aceito em: 09/03/2020. 